\title{
Evaluation of water treatment characteristics at the improved circle secondary settling basin
}

\author{
개량 고속원형침전지의 수처리 특성 평가
}

\author{
Honggyu Jang ${ }^{{ }^{*}} \cdot$ Youngman $\mathrm{Cho}^{2} \cdot$ Changwon $\mathrm{kim}^{3}$ \\ 장홍규 $^{1^{*}} \cdot$ 조영만 ${ }^{2} \cdot$ 김창원 $^{3}$ \\ 'Saman Corporation - ${ }^{2}$ Busan Water Authority · ${ }^{3}$ Department of Environmental Engineering in Pusan National university \\ '주)삼안 · 부산광역시상수도사업본부 · ${ }^{3}$ 부산대학교 환경공학과
}

\begin{abstract}
Researcher of this study improved conventional circle secondary settling basin, through the way such as extend of inlet pipe length, introduction of device for inducting uniforming of flow, keeping of height of sludge interface. Also, we compared conventional circle settling basin to improved circle settling basin the water treatment efficiency. Result of research, when SVI is average 117, improvement rate of SS and BOD were 51.0\%, 37.0\% approximately compared to conventional settling basin. And when SVI is average 178, improvement rate of SS and BOD were 22.7\%, 36.0\% approximately. Also when SVI is average 196 , improvement rate of SS and BOD were $24.7 \%, 30.3 \%$ approximately. When it' s winter, improvement rate of SS, BOD, COD, TN and TP were 20.6\%, 17.9\%, 13.9\%, 13.5\%, 12.4\% approximately. Therefore, we can be the judge, this improved settling basin can be used as the final settling basin in the waste water treatment plant.
\end{abstract}

Key words : Circle settling basin, Device for inducting uniforming, Height of sludge interface 주제어 : 원형침전지, 정류유도장치, 슬러지층 높이

\section{1. 서 론}

하수 처리공정은 다양한 물리, 화학, 생물학적, 단위공정의 조합으로 구성되어 있고 그 중에서 침 전 공정에 하수처리 공정에서 매우 중요한 공정 중에 하나이다(Choei, 2010). 침전은 입자와 혼 탁 된 유체 중에서 입자를 분리하는 공정으로 침 전 가능한 입자상 물질의 대부분을 중력에 의하여 제거한다. 통상적으로 침전지의 형식으로는 침전 지의 형태에 따라, 단충, 복층, 횡류식장방형, 원 형, 상향류식 등으로 분류할 수 있는데 이 중에서 원형침전지는 침전된 슬러지의 체류시간이 짧고

- Received 02 September 2014, revised 30 September 2014, accepted 02 October 2014. * Corresponding author: Tel : 010-9180-5649 E-mail : hkjang@samaneng.com
슬러지 수집 장치가 간단하여 유지비가 적게 드는 장점뿐만 아니라 공간 활용도가 높아 도심지, 택 지 혹은 공장 단지 내에서 중소형의 침전지로 사 용될 경우 매우 유리하며 특히 슬러지 농축시설은 대부분 원형침전지가 활용되고 있다(Kim, 2006, Ekama., 2004, Ghawi., 2004). 여러 장점에도 불구하고 원형침전지는 유입관을 통해 유입되어 진 유입수는 유입 유입정에서 방사상의 원주방향 으로 흘러 침전지 측면 벽체를 타고 일부는 웨어 로 유출되고 일부는 유입정 쪽으로 선회류를 형성 하기도 하며 또한 유입정에서 하강하는 유속의 분 포는 균일한 것이 유리하지만, 유입정 내에 젯트 류 및 농도 구배, 유입정 구조물 등의 요인으로 인 하여 와류가 발생할 경우 유선이 콘크리트 벽면에 
부착하여 국부적으로 속도를 증가시켜 단락류를 발생시키는 위험성이 존재한다(Glover., 2004, Jemsen., 2004, Merlo., Minasny., 2004, Watts., 2004). 유입정을 빠져나온 고농도의 유입수는 유입관을 타고 수직 하강하여 원형호 퍼 내에 적체된 슬러지를 교란하여 재 부상시키 는 단점을 안고 있다(Lakehal., 2004, Lanberta., 2004).

본 연구에서는 이와 같은 기존 원형침전지가 안고 있는 단점을 해결하기 위해 기존 원형침전 지 유입정 아래에 본 연구자들이 고안한 8개의 원형파이프가 방사형으로 연결되어 있는 일명 “ 정류유도장치"를 부착하여 유입정에서 빠져나오 는 유입수에 선회류를 부여하여 슬러지층을 교 란하지 않으면서 유입수를 침전지 내에 고루 분 산시키는 원활을 하도록 하였고 원수 유입정 역 시 기존 원형침전지에 비해 바닥 방향으로 연장 하여 슬러지 층 내로 유입수를 유입시켜 탁질 포 집효과를 높이고자 하였다. 따라서 본 연구는 기 존 원형침전지에 원수 유입정 연장, 정류유도장 치 부착, 슬러지층 높이 유지 등의 세 가지 점을 개선하여 기존 원형침전지와 수처리 효율을 비 교 평가하였다.

\section{2. 연구 장치 및 방법}

\section{1 장치 및 구성}

본 연구 대상 공정인 개량원형침전지의 기본 형태는 Fig. 2 와 같은 구성되어 있다. 이 중에서 정류유도장치는 Fig. 3과 같이 방사형으로 배치 된 파이프 형태이다. Fig. 2와 같이 개량원형침 전지는 기본적으로 Fig. 1 의 기존 원형침전지에 비해 원수 유입정이 약 $30 \%$ 정도 아래 방향으 로 연장되어 있고 또한 슬러지 층의 높이 역시 기존 침전지에 비해 높게 유지되어 유입수가 슬 러지 층 내로 유입되는 구조로 되어있다. 따라 서 개량고속원형침전지는 기존의 원형침전지에 비해 다양한 수처리 효과를 기대할 수 있다. 첫 째로 슬러지 층의 높이가 높아짐으로써 슬러지
의 자체 무게가 증가되면서 침전지 바닥에 압밀 침전층의 슬러지 밀도가 높아져 슬러지의 농축 율을 높일수 있고 슬러지의 탈수율을 향상시킬 수 있다. 둘째로는 원수가 슬러지 전이층으로 유 입되기 때문에 슬러지 층 생물 플록에 의한 걸 림(enmeshment), 물리화학적 흡착에 의한 콜 로이드물질 제거, 미생물에 의한 용해서 유기물 의 생물흡착(biosorption) 등의 작용에 의해 기 존 침전지가 침강 하나만의 공정에 의해 탁질에



Fig. 1. Conventional circle settling basin.

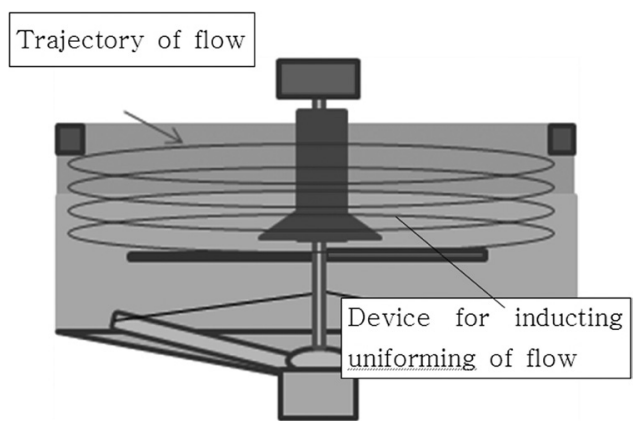

Fig. 2. Improved circle settling basin.

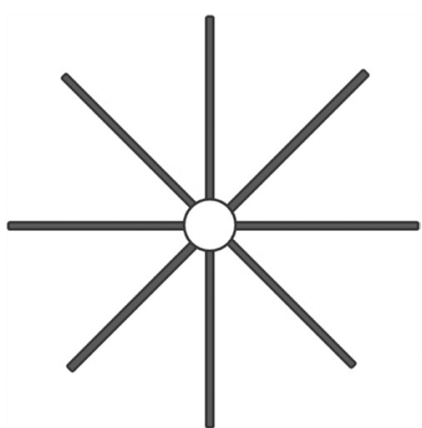

Fig. 3. Device for inducting uniforming of flow in improved circle settling basin. 
제거되는 것보다 수처리 효과가 크게 개선되게 된다. 셋째로 유입된 원수가 정류유도장치의 회 전에 의해 분산되기 때문에 기존 원형침전지 내 에서 형성된 사구간을 해소할 수 있고 또한 기 존 원형침전지 내에서 수질 방향 유동궤적이 형 성된 것이 원형의 선회류 형태로 유동궤적이 개 선되어 탁질의 침강, 흡착, 걸림 등의 탁질 제거 공정의 시간이 크게 증가되면서 수처리 효과가 향상되게 된다.

\section{2 연구 방법}

실험대상 시설은 양산시 y 공단 폐수종말처리 장 2 차침전지에 대해 원수유입관을 연장하고 정 류유도장치로 개량하여 실험하였다. 대상 2차침 전지의 용량은 $904.32 \mathrm{~m}^{3}(\mathrm{D} 16 \mathrm{~m} \times \mathrm{H} 4.5 \mathrm{~m})$ 으로 체류시간 $3.37 \mathrm{hr}$, 수면적부하 $27.9 \mathrm{~m}^{3}$ / $\mathrm{m}^{2} \cdot \mathrm{d}$ 로 설계되어 있으며, 일 최대 유입유량은 $12,000 \mathrm{~m}^{3} / \mathrm{d}$ 이다. 실험 당시의 실제 수류학적 체류시간은 봄, 여름철의 경우는 $7.14 \mathrm{hr}$ 이었고 가을 겨울철에는 $9.8 \mathrm{hr}$ 이었다.

의뢰 샘플에 대한 시험은 KORAS 인증기관인 한국융학과학연구원이었다. 채취는 2 리터 멸균 채수용기를 사용하였고 채취된 시료는 냉장용기 에 담아 즉시 시험기관에 운송하여 시험을 의뢰

Table 1. Sampling point and measurement item

\begin{tabular}{|c|c|}
\hline Sampling point & Measurement item \\
\hline Imput & SS, SVI \\
\hline Output & SS, BOD, COD, SS, TN, TP \\
\hline
\end{tabular}

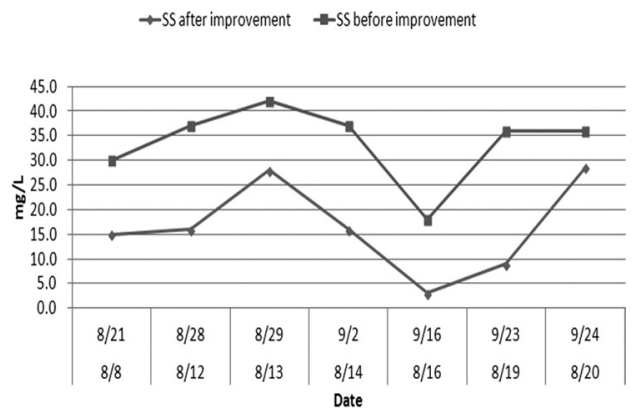

Fig. 4. SS of output to before and after improvement(SVI 117).
하였다. 현장 측정항목인 슬러지 높이와 슬러지 침강성은 현장에서 시험하였다. 채수지점 및 측 정항목은 Table 1 과 같다.

\section{3. 결과 및 고찰}

\section{1 슬러지 침강성(SVI)에 따른 수질개선 효과}

실험대상 원형침전지는 지방산업공단 공장폐 수를 처리하는 폐수종말처리장의 2 차 침전지이 다. 공장폐수를 처리하는 폐수종말처리장 원수 는 일반 도시하수처리장 원수보다 플록의 침강 성이 나쁜 것으로 알려져 있다. 하수처리장의 침 전지의 계면은 육안으로 확인하기도 어렵기 때 문에 계면기가 설치되어 있지 않는 경우 슬러지 높이를 일정하게 유지하기 매우 어려운 것이 현 실이다. 이러한 현실을 감안하여 본 실험에서는 2 차 침전지 1 지에 대해, 개선 전에는 슬러지 계 면을 원수 유입관 이하로 유지하고 개선 후에는 슬러지 계면 높이를 원수 유입관 위쪽으로 높이 형성시키는 조건으로 실험을 하면서 각각의 유 출수질을 비교 분석하였다. 슬러지 계면을 실험 자가 직접 계면 측정기를 이용하여 측정하면서 실험을 수행하였다.

Fig. 4는 고수온인 8월 9월에 실험을 하여 유 출수의 부유물질 농도를 비 부유물질(SS) 분석 하였다. 실험 기간 동안 유입 원수의 SVI값은 평 균 117 이었다. 실험 결과 개선 후가 개선 전보다 월류수 $\mathrm{SS}$ 가 약 $51 \%$ 개선되는 것으로 나타났다. Fig. 5는 개선 전과 개선 후의 유출수 중에 $\mathrm{BOD}$



Fig. 5. BOD of output to before and afterimprovement(SVI 117). 


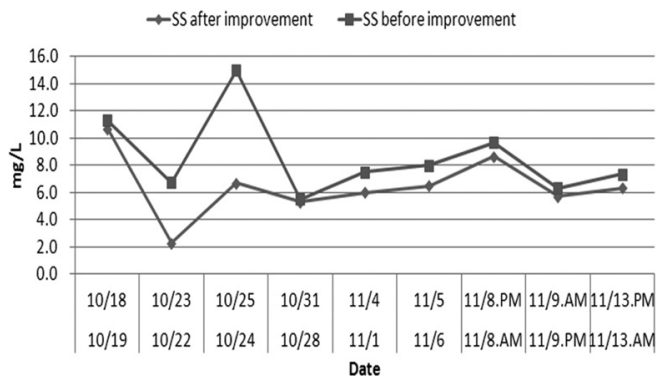

Fig. 6. SS of output to before and after improvement(SVI 199).



Fig. 8. SS of output to before and after improvement(SVI 178).

값을 비교한 것으로 개선 후에 유출수 $\mathrm{BOD}$ 가 향 상되는 것으로 나타났다. 개선 후 평균 $\mathrm{BOD}$ 는 $18.2 \mathrm{mg} / \mathrm{L}$ 이었고 개선 전에는 평균 $11.5 \mathrm{mg} / \mathrm{L}$ 로 개선율은 약 $37 \%$ 로 나타났다. 이와 같은 결 과는 슬러지 층에서 생화학적 포집과 플록의 응 집이 주요 원인인 것으로 판단된다.

Fig. 6, 7은 10월과 11월 수온이 낮아지면서 SVI 값이 199으로 높아졌을 때 SS와 BOD값의 변화를 나타낸 그래프이다. Fig. 6은 월류수 SS 농도를 나타낸 그래프로 개선 전에 평균 $\mathrm{SS}$ 는 $8.6 \mathrm{mg} / \mathrm{L}$ 이었고 개선 후에는 평균 $6.56 \mathrm{mg} /$ $\mathrm{L}$ 로 향상되어 개선율은 약 $24.7 \%$ 로 나타났다. Fig. 7은 월류수 BOD를 나타낸 그래프로 개선 전에는 평균 $\mathrm{BOD}$ 는 $12.2 \mathrm{mg} / \mathrm{L}$ 이었고 개선 후 에는 평균 $7.9 \mathrm{mg} / \mathrm{L}$ 로 향상되어 개선율은 약 $30.3 \%$ 로 나타났다. 따라서 SVI 199의 비교적 침전성이 좋지 않은 슬러지에서도 본 개선 원형 침전지에의 경우 수질 개선 효과를 얻을 수 있는 것을 확인할 수 있다.

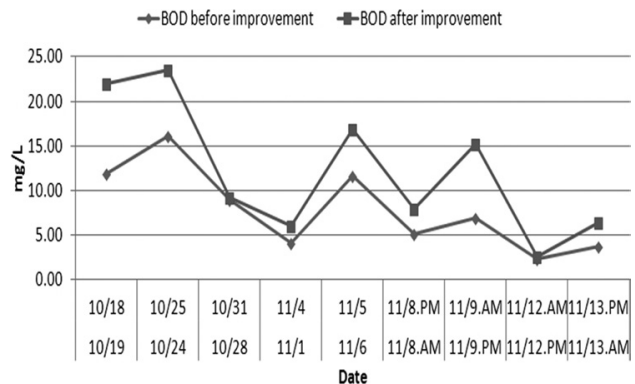

Fig. 7. BOD of output to before and after improvement(SVI 199).

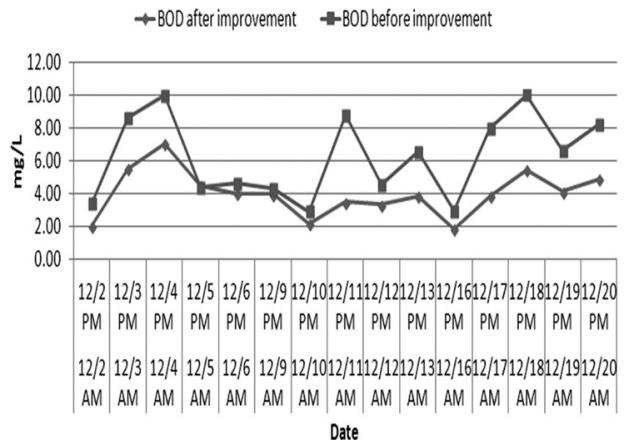

Fig. 9. BOD of output to before and after improvement(SVI 178).

Fig. 8, 9는 12 월 SVI 값이 178 인 경우 SS와 $\mathrm{BOD}$ 값의 변화를 나타낸 그래프이다. 10월과 11 월에 비해 SVI 값이 조금 감소한 것은 포기조 내 에 미생물 활성제를 투여하여 침강성이 개선되 었기 때문이다. Fig. 8은 월류수 SS 농도를 나 타낸 그래프로 개선 전에 평균 $\mathrm{SS}$ 는 $5.72 \mathrm{mg} / \mathrm{L}$ 이었고 개선 후에는 평균 $4.42 \mathrm{mg} / \mathrm{L}$ 로 향상되 어 개선율은 약 $22.7 \%$ 로 나타났다. Fig. 9는 월 류수 $\mathrm{BOD}$ 를 나타낸 그래프로 개선 전에는 평균 $6.30 \mathrm{mg} / \mathrm{L}$ 이었고 개선 후에는 평균 $4.03 \mathrm{mg} /$ $\mathrm{L}$ 로 향상되어 개선율은 약 $36.0 \%$ 로 나타났다.

Fig. 10은 SVI 값의 변동 즉 슬러지 침강성에 따른 $\mathrm{SS}$ 와 $\mathrm{BOD}$ 의 개선율을 나타낸 그래프이 다. 그림에서와 같이 개선율이, SVI 약 100 에서 $\mathrm{SS}$ 는 약 $51 \%, \mathrm{BOD}$ 는 $37 \%$ 이었고, SVI 약 200 에서는 $\mathrm{SS}$ 약 $25 \%, \mathrm{BOD}$ 는 약 $30 \%$ 개선되는 것으로 나타났다. 따라서 침강성 SVI 200 까지 본 개량형 원형침전지가 폐수 처리장의 슬러지 에 활용이 가능할 것을 판단된다. 


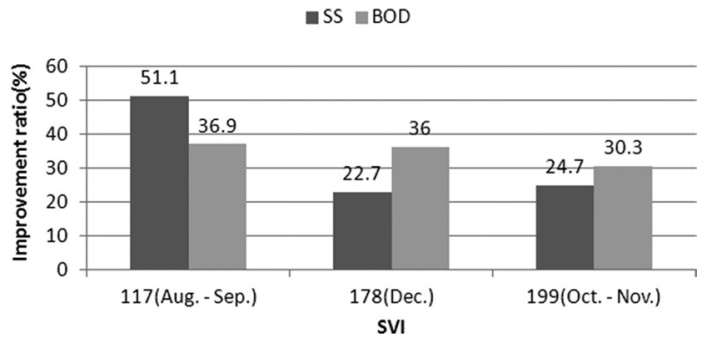

Fig. 10. Improvment effect of SS and BOD according to SVI.

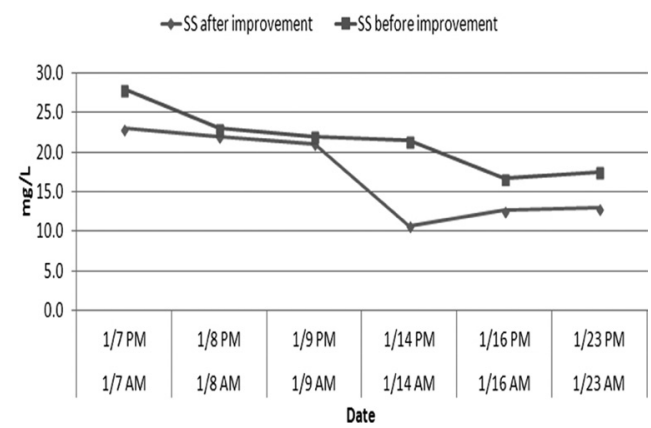

Fig. 11. SS of output to before and afterimprovement at the winter.

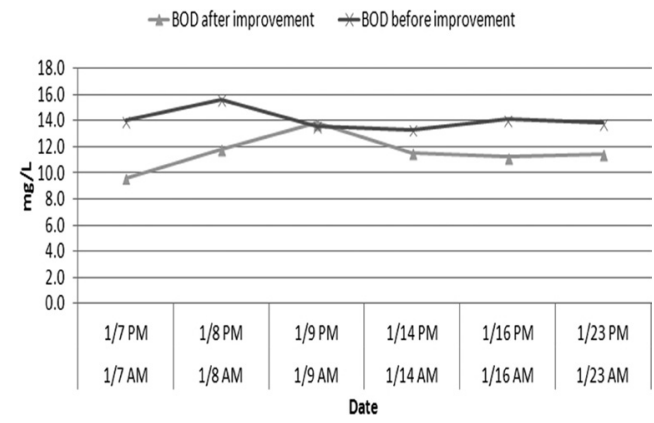

Fig. 12. BOD of output to before and after improvement at the winter.

\section{2 동절기 실험}

Fig. 11은 동절기에 해당하는 1 월 평균 $\mathrm{SS}$ 농 도 변화를 나타낸 것으로 개선 전 부유 물질의 평 균 농도는 $21.5 \mathrm{mg} / \mathrm{L}$ 이었고 개선 후에는 17.0 $\mathrm{mg} / \mathrm{L}$ 로 개선 율은 약 $20.6 \%$ 이었다. Fig. 12 는 같은 시기 평균 $\mathrm{BOD}$ 농도를 나타낸 그래프로 그 림에서와 같이 개선 전 평균 $\mathrm{BOD}$ 농도는 14.1 $\mathrm{mg} / \mathrm{L}$ 이었으나 개선 후에는 $11.6 \mathrm{mg} / \mathrm{L}$ 로 향상 되어 개선 율은 약 $17.9 \%$ 를 나타내었다.

Fig. 13은 동절기 평균 $\mathrm{COD}$ 농도를 나타낸



$$
\text { Date }
$$

Fig. 13. COD of output to before and after improvement at the winter.

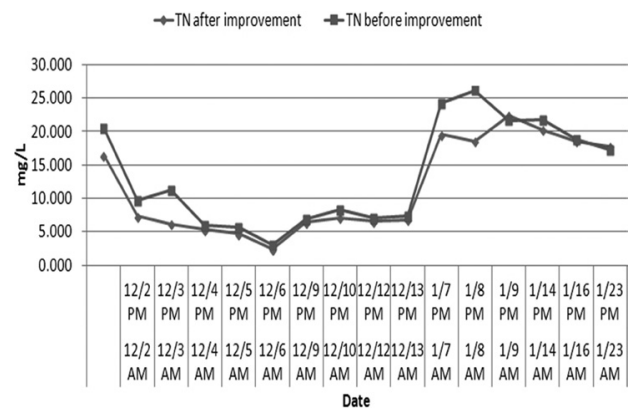

Fig. 14. TN of output to before and after improvement at the winter.

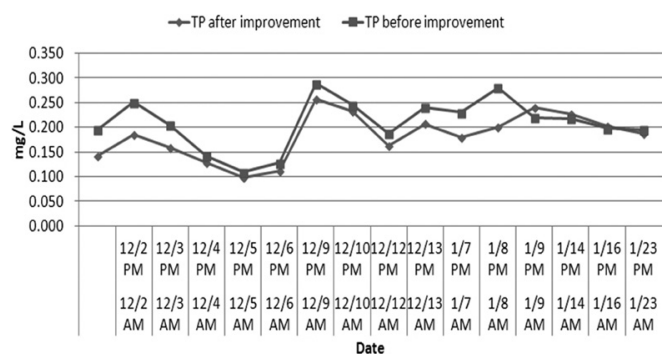

Fig. 15. TP of output to before and after improvement at the winter.

그래프로 그림에서와 같이 개선 전 평균 $\mathrm{COD}$ 농 도는 $38.38 \mathrm{mg} / \mathrm{L}$ 이었으나 개선 후에는 33.03 $\mathrm{mg} / \mathrm{L}$ 로 향상되어 개선 율은 약 $13.9 \%$ 를 나타 내었다. Fig. 14는 동절기 평균 총질소 농도 변 화를 나타낸 것으로 개선 전 총질소 평균 농도는 $13.5 \mathrm{mg} / \mathrm{L}$ 이었고 개선 후에는 $11.7 \mathrm{mg} / \mathrm{L}$ 로 개 선 율은 약 $13.5 \%$ 이었다.

Fig. 15 는 같은 시기 평균 총인 농도를 나타낸 그래프로 그림에서와 같이 개선 전 평균 총인 농 
도는 $0.208 \mathrm{mg} / \mathrm{L}$ 이었으나 개선 후에는 0.182 $\mathrm{mg} / \mathrm{L}$ 로 개선되어 개선 율은 약 $12.4 \%$ 를 나타 내었다. 이와 같은 동절기 실험 결과로 미루어 보아 하숲처리장 2차침전지 용도로 개량 원형 침전지 적용이 충분히 가능한 것으로 판단된다.

\section{4. 결 론}

하수처리장 2 차 침전지에 대하여 개량원형침 전지을 적용한 실험결과 다음과 같은 결론을 얻 었다.

1) 하절기 슬러지 침강성(SVI 평균 117)이 양 호한 시기에 개량원형침전지는 기존 침전 지에 비해 부유물질(SS)은 약 $51 \%$ 개선되 었고 $\mathrm{BOD}$ 는 약 $37 \%$ 개선률은 나타내었다.

2) 가을철 수온이 낮아지고 슬러지 침강성이 불량해지는 SVI 값이 178 인 경우 SS의 평 균 개선율은 약 $22.7 \%, \mathrm{BOD}$ 개선율은 약 $36.0 \%$ 이었고, SVI 196 인 경우 SS 개선율 은 약 $24.7 \%, \mathrm{BOD}$ 는 약 $30.3 \%$ 로 나타나 SVI 값이 약 200 까지는 본 개량침전지의 적용이 가능한 것으로 확인되었다.

3) 동절기에 해당하는 1 월 평균 $\mathrm{SS}$ 개선율 은 약 $20.6 \%, \mathrm{BOD}$ 는 약 $17.9 \%, \mathrm{COD}$ 개 선 율은 약 $13.9 \%$, 총질소 개선 율은 약 $13.5 \%$, 총인 개선 율은 약 $12.4 \%$ 를 나타 내어 동절기에도 본 개량형원형침전지의 적용이 가능한 것으로 판단된다.

\section{References}

Choi, Y.G., Bae, K.H. and Yoon, J.H., "Optimization of influent and effluent baffle configuration of a rectangular secondary clarifier using CFD and PIV test, (2010) “J. KSWW, Vol. 24, No 1, pp. 41-50.

Kim, S .S., Park, N.S., Moon, Y.T. and Lee, S.J., (2006) "Case study on remodeling outlet structure within a sedimentation basin for improving performance," J. KSWW, Vol. 20, No. 6, pp. 911-918.

Ekama, G.A. and Marais, P., (2004) "Assessing the applicability of the 1D flux theory to full scale secondary settling tank design with a 2D hydrodynamic model, Water. Res., Vol. 38, pp. 495-506.

Ghawi, A.G. and Kriš Improvement performance of secondary clarifiers by a computational fluid dynamics model, Slovak, (2004) "J. of Civil Eng., Vol. 19, No. 4, pp. 1-11.

Glover, G.C., Printemps, C., Essemiani, K. and Meinhold, J., "Modelling of wastewater treatment plant - how far shall we go with sophisticated modelling tools?, (2004) "Water Sci. Technol., Vol. 53, No. 3, pp. 79-89.

Jensen, M.D., Ingildsen, P., Rasmussen, M.R. and Laursen, J.. "Computational fluid dynamics modelling of hydraulics and sedimentation in process reactors during aeration tank settling, (2004) "Water Sci. Technol., Vol. 53, No. 12, pp. 257-264.

Merlo., R.P., Esping, D., Jimenez, J., Campanella, K., Freedman, S., Parker, D., ahlberg, E., Witzgall, B. and Caldwell., B., (2004) "Getting more out of secondary clarifiers for wet weather flow management using state of the art tools, WEFTEC 2006, Water Environment Foundation, pp. 292-309.

Minasny, B. and McBratney, A.B. (2004) "A conditioned Latin hypercube method for sampling in the presence of ancillary information," Computers \& Geosciences, Vol. 32, No. 9, pp. 1378-1388.

Watts, R.W., Svoronos, S.A. and Koopman, B., (2004) "One dimensional modelling of secondary clarifiers using a concentration feed velocity dependent dispersion coefficient,"Water. Res., Vol. 30, No. 9, pp. 2112-2124.

Lakehal, D., (2004) "On the modelling multiphase turbulent flows for environmental and hydrodynamic applications, Multiphase Flow," Vol. 28, pp. 823-863.

Lamberto, D.J., Alvarez, M.M. and Muzzio, F.J., (2004) "Experimental and computational investigation of the laminar flow structure in a stirred tank," Chem. Eng. Sci., Vol. 54, pp. 919-942. 